\title{
Bending moment capacity of stainless steel-concrete composite beams
}

\author{
R. Shamass ${ }^{a}$, K.A. Cashell ${ }^{b^{*}}$ \\ ${ }^{a}$ Division of Civil and Building Services Engineering, School of Build Environment and Architecture, London \\ South Bank University, UK \\ ${ }^{\mathrm{b}}$ Dept of Civil and Environmental Engineering, Brunel University London, UK \\ * corresponding author, e-mail address: katherine.cashell@brunel.ac.uk
}

\begin{abstract}
Stainless steel is increasingly popular in construction owing to its corrosion resistance, excellent mechanical and physical properties as well as its aesthetic appearance. The current paper is concerned with the use of stainless steel in steel-concrete composite beams, which is a new application. Current design codes for steel-concrete composite beams neglect strain hardening in the steel. Whilst this is a reasonable assumption for carbon steel, stainless steel is a very ductile material which offers significant levels of strain hardening prior to failure. Therefore, when current design provisions are applied to stainless steel composite beams, the strength predictions are generally inaccurate. The current study presents a simplified analytical solution that takes into consideration the strain hardening of stainless steel when bending moment capacity is calculated. A finite element model is developed and validated against a number of experimental results for composite beams. The validated numerical model is then used to investigate the accuracy of the proposed analytical solution. It is concluded that simplified analytical solution is reliable and provides a straightforward design tool for practicing engineers who wish to specify this novel construction form in appropriate applications.
\end{abstract}

Keywords: Stainless steel; composite beams; finite element analysis, analytical analysis; continuous strength method; Eurocodes

\section{Introduction}

Composite steel-concrete members are widely used in the design and construction of modern structures such as bridges and high rise buildings. Due to the composite action, a significant increase in strength and stiffness can be achieved compared with bare steel or concrete sections, depending on the degree of shear connection between the steel and concrete. This results in savings not only in construction depth but also in steel and concrete consumption, which reduces the environmental impact of the structure.

Stainless steels have been used in structures since the 1920s when the main application was for building facades. Nowadays, stainless steels have become popular in a wide range of construction applications due to their excellent mechanical properties such as high strength, excellent retention of strength and stiffness at high temperature [1] as well as their corrosion resistance properties. Stainless steels do not require protective coatings to prevent corrosion and therefore can offer significant cost savings compared with carbon steel over the life cycle of the structure [2]. In addition to these qualities, stainless steels also have greater ductility and capacity for work hardening compared to carbon steels. A ductile cross-section is necessary for plastic design and is highly desirable for design in general so that warning is given before collapse and for moment redistribution to occur.

In recent years, as its usage in building structures has increased, stainless steel has been the subject of intensive research to understand their behaviour in load-bearing applications and to provide efficient and reliable design guidance. The vast majority of research studies have been focussed on bare steel elements (e.g. [3-5]) as 
well as a few studies into concrete-filled stainless steel tubular sections (e.g. [6-8]). There has been no research, at least not in the public domain, into the behaviour of composite beams made from stainless steel.

According to current design codes, the plastic bending resistance of composite steel-concrete beams is determined by rigid-plastic theory in which the effective area of the steel member is stressed to its yield strength, neglecting any stain hardening in the steel. Although this is a reasonable assumption for carbon steel which has an elastic response, with a clearly defined yield point, followed by a yield plateau and a moderate degree of strain hardening, stainless steel has significant levels of strain hardening prior to failure which should be accounted for. Accordingly, utilising the current design codes for composite beams, for members made using stainless steel, results in incorrect predictions of the plastic bending resistance.

In this context, the current study presents a simplified analytical solution for estimating the bending moment capacity of stainless steelconcrete composite beams with a full shear connection subjected to sagging moments. The proposed solution is an adaptation of the continuous strength method (CSM), which has been developed and validated extensively in recent years for structural steel (e.g. [9]), structural stainless steel (e.g. [10]) and, more recently, for carbon steel-concrete composite beams [11]. Since there are no tests available for stainless steel-concrete composite beams, a nonlinear finite element model is developed and used to investigate the accuracy of the proposed analytical solution.

\section{Simplified analytical model for stainless steel-concrete composite beams with a full shear connection}

The full-range stress-strain relationship for stainless steel which has been presented in the literature (e.g. [12]) describes strain as an explicit function of stress. However, in order to use the CSM in conjunction with an accurate material law for stainless steel, it is necessary to define the stress as an explicit function of strain. Abdella [13] proposed an approximate inversion relationship with the stress $(\sigma)$ expressed as an explicit function of strain $(\varepsilon)$, as follows:

$$
\begin{aligned}
& \sigma_{1}(\varepsilon)=\sigma_{0.2} \frac{r\left(\frac{\varepsilon}{\varepsilon_{0.2}}\right)}{1+(r-1)\left(\frac{\varepsilon}{\varepsilon_{0.2}}\right)^{p}} \quad \text { for } \quad \varepsilon \leq \varepsilon_{0.2} \\
& \left.\sigma_{2}(\varepsilon)=\sigma_{0.2} 1+\frac{r_{2}\left[\frac{\varepsilon}{\frac{\varepsilon}{\varepsilon_{0.2}}-1}\right]}{\left\lfloor 1+\left(r^{*}-1\right)\left(\frac{\frac{\varepsilon}{\varepsilon_{0.2}}-I}{\frac{\varepsilon_{0 .}}{\varepsilon_{0.2}}-1}\right)^{p^{*}}\right.}\right] \text { for } \\
& \varepsilon^{>} \varepsilon_{0.2}
\end{aligned}
$$

where the material parameters are:

$$
\begin{array}{lrl}
\varepsilon_{0.2}=\frac{\sigma_{0.2}}{E}+0.002 & r=\frac{E \varepsilon_{0.2}}{\sigma_{0.2}} \\
E_{2}=\frac{E}{1+0.002 n / e} & p=r \frac{1-r_{2}}{r-1} \\
e=\frac{\sigma_{0.2}}{E} & m=1+3.5 \frac{\sigma_{0.2}}{\sigma_{u}} \\
\sigma_{u}=\sigma_{0.2} \frac{1-0.0375(n-5)}{0.2+185 e} & E_{u}=\frac{E_{2}}{1+\left(r^{*}-1\right) m} \\
r_{2}=\frac{E_{2} \varepsilon_{0.2}}{\sigma_{0.2}} & r_{u}=\frac{E_{u}\left(\varepsilon_{u}-\varepsilon_{0.2}\right)}{\sigma_{u}-\sigma_{0.2}} \\
\varepsilon_{u}=m i n\left(1-\frac{\sigma_{0.2}}{\sigma_{u}}, A\right) & p^{*}=r^{*} \frac{1-r_{u}}{r^{*}-1} \\
r^{*}=\frac{E_{2}\left(\varepsilon_{u}-\varepsilon_{0.2}\right)}{\sigma_{u}-\sigma_{0.2}} &
\end{array}
$$

In these expressions, $\sigma_{0.2}$ is $0.2 \%$ proof strength, $\varepsilon_{0.2}$ is the total $0.2 \%$ strain corresponding to $\sigma_{0.2}$, $n$ is a strain hardening coefficient, $\varepsilon_{u}$ is the ultimate tensile strain, $A$ is the stainless steel elongation, $E_{2}$ and $E_{u}$ are the slope of the stressstrain curve at $\varepsilon_{0.2}$ and $\varepsilon_{u}$, respectively, and $r, r_{2}$, $r^{*}, r_{u}, p, p^{*}$ and $m$ are parameters that need to be determined.

Fig. 1 illustrates the strain distribution through the depth of the cross-section for composite beams with a full shear connection together with the corresponding stress distribution obtained using the material model presented in Eqs. 1 and 2. In this figure, $\varepsilon_{s}$ and $\varepsilon_{c}$ are the strain at the bottom fibre of the stainless steel beam and top fibre of the concrete slab, respectively. It is noteworthy that the actual stress distribution in the stainless steel section is nonlinear. 


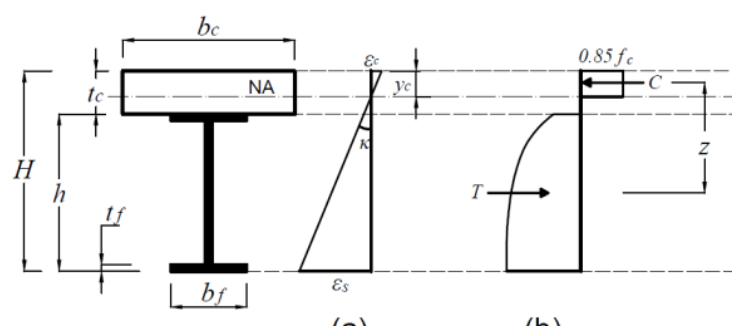

(a)

(b)

Fig. 1: (a) Strain and (b) stress distribution diagrams for composite beams with full shear connection

The position of the plastic neutral axis (NA), $y_{c}$, can be obtained by applying horizontal equilibrium (i.e. $C=T$, where $C$ and $T$ are the total internal compressive and tensile forces in the section, respectively), and the plastic moment capacity of the composite section $\left(M_{p l}\right)$ can be obtained from $M_{p 1}=T^{*} z$, where $z$ is the lever arm of the internal forces $C$ and $T$.

In these expressions, $C$ and $T$ are determined from Eqs. 3 and 4, respectively:

$$
\begin{aligned}
& C=0.85 f_{c} y_{c} b_{c} \\
& T=\int \sigma(\varepsilon) d A
\end{aligned}
$$

Also, $\sigma(\varepsilon)$ is the stress function, calculated using Eqs. 1 and 2.

The lever arm $(z)$ be obtained from Eq. 5:

$$
z=\frac{y_{c}}{2}+\frac{\int \sigma(\varepsilon) y d A}{T}
$$

In this expression, $y$ is the distance between a fibre of the stainless steel beam and the neutral axis (NA).

In order to calculate the internal force $T$ and the lever arm $z$, direct integration is impossible to achieve; therefore, numerical integration is required which may not be suitable for a straightforward design tool. In order to simplify the calculations, the actual stainless steel stress block is replaced with an equivalent rectangular stainless steel stress block, in the current paper. Hence, a stainless steel stress of $\sigma_{t}$ is assumed to be distributed over an equivalent tension zone bounded by the edges of the cross-section of the stainless steel beam, where $\sigma_{t}$ is selected as the stress at $60 \%$ of the steel beam height, as shown in Fig. 2. This concept is similar to that employed in the design of concrete crosssections, where the parabolic compressive stress in the material is idealised as an equivalent rectangular stress block.

The simplified analytical model developed in this section is based on the following assumptions:

- The NA is within the concrete slab. Hence, the compressive force in the concrete is larger than the tensile force in the steel element.

- The slip that occurs between the steel section and the concrete slab is assumed to be negligible and therefore is ignored.

- Plane sections before bending remain plane after bending. Therefore, the strain distribution over the composite crosssection is linear with constant curvature, $\kappa$.

- Any reinforcement in the concrete slab is ignored in the calculations.

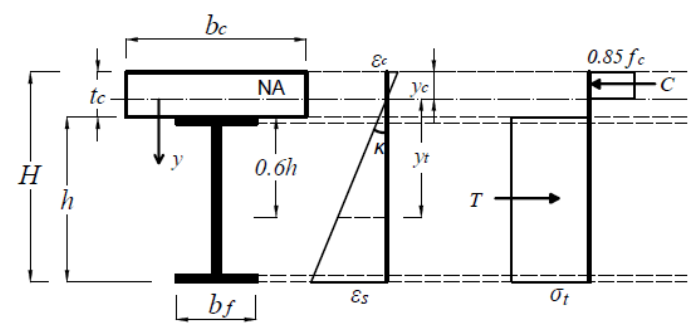

(a)

(b)

Fig. 2: (a) Strain and (b) stress distribution diagrams for composite beams with full shear connection based on the simplified analytical model

From the strain distribution diagram shown in Fig. 2, the distance between the NA and the location where the stress of the stainless steel is $\sigma_{t}$ (i.e. $y_{t}$ ) can be determined by:

$$
y_{t}=t_{c}+0.6 h-y_{c}
$$

where $y_{c}$ is the height of compressive area of the concrete slab.

From horizontal equilibrium of the internal axial forces:

$$
\begin{aligned}
C & =T \rightarrow 0.85 f_{c} y_{c} b_{c}=A_{s} \sigma_{t} \\
& \text { or } \\
y_{c} & =\frac{A_{s}}{0.85 f_{c} b_{c}} \sigma_{t}
\end{aligned}
$$

where $A_{s}$ is the cross-sectional area of the stainless steel member.

It is assumed that $y_{t} \geq y_{0.2}$, and therefore: 


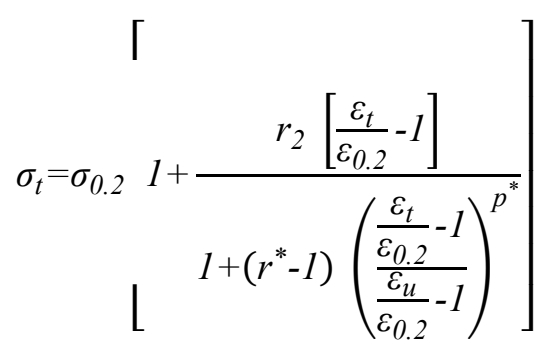

where $\varepsilon_{t}$ is the strain in the steel section at $y_{t}$ and $\kappa$ is the cross-sectional curvature, determined from:

$$
\begin{aligned}
& \varepsilon_{t}=\kappa y_{t}=\kappa\left(t_{c}+0.6 h-y_{c}\right) \\
& \kappa=\min \left(\kappa_{c}, \kappa_{a}\right)
\end{aligned}
$$

$y_{0.2}$ is the distance between the NA and the location in the cross-section where the strain in the stainless steel section is $\varepsilon_{0.2}$, and is found from:

$y_{0.2}=\frac{\varepsilon_{0.2}}{\kappa}$

$\kappa_{c}$ is the curvature when the strain at the outer concrete fibre reaches the ultimate strain of concrete, $\varepsilon_{c u}$, and can be determined from:

$$
\kappa_{c}=\varepsilon_{c u} / y_{c}
$$

The nominal ultimate strain of concrete $\left(\varepsilon_{c u}\right)$, as a percentage, is given in Eurocode 2 [14] as:

$$
\begin{aligned}
& \varepsilon_{c u}=2.6+35\left[\left(98-f_{c}\right) / 100\right]^{4} \\
& \text { for } f_{c} \geq 50 \mathrm{~N} / \mathrm{mm}^{2}, \text { otherwise } 3.5
\end{aligned}
$$

$\kappa_{a}$ is the curvature when the strain at the outer stainless steel fibre reaches the ultimate strain of the stainless steel, $\varepsilon_{u}$, and can be determined from:

$$
\kappa_{a}=\varepsilon_{u} /\left(H-y_{c}\right)
$$

$\kappa_{c}$ and $\kappa_{a}$ define the governing failure mode of the composite member: if $\kappa_{c}<\kappa_{a}$, the composite beam fails due to concrete crushing whereas steel failure dominates when $\kappa_{c}>\kappa_{a}$.

The position of the NA (i.e. $y_{c}$ ) can be determined using Eq. 7 together with Eqs. 8-14 using a trial and error technique. Finally, the plastic bending capacity of the composite beam can be calculated as:

$$
M_{p l}=\sigma_{t} A_{s}\left[H-h / 2-y_{c} / 2\right]
$$

\section{Development of the numerical model}

There are no tests available in the literature on the flexural behaviour of composite stainless steel-concrete beams. Therefore, a numerical model is developed in the current section to examine the proposed analytical model. Shamass and Cashell [15] previously developed finite element (FE) model using ABAQUS [16] for composite concrete-steel beams made from either normal or high strength materials. It was demonstrated that the numerical model is capable of accurately predicting the behaviour of composite beams in terms of bending moment capacity, initial bending stiffness and interaction performance for composite members with full or partial shear connection. Therefore, the same numerical model is adopted herein to examine the proposed analytical solution for stainless steel-concrete composite beams. A brief description of the model is included hereafter; a more detailed description can be found elsewhere [15].

The concrete slab and steel beams are modelled using shell elements with reduced integration, namely the S4R element in ABAQUS. The shear studs are modelled using Cartesian connectors which connect a node in the beams flange with a coincident node in the slab at the connector location. The nonlinear load-slip relationship of the shear connectors is modelled based on the relation proposed by Ollgaard et al. [17]. In the current FE model, the strength of the shear connection is assumed to equal the total compressive normal force in the concrete flange divided by the number of shear studs in the shear span (i.e. $P_{\text {stud }}=C / N$ where $N$ is the number of shear connectors in the shear span).

The point loads on the top surface of the composite beam are applied in displacement control. A hard contact without friction is used to simulate the interaction between the concrete slab and the steel beam. The implicit dynamic solution method for quasi-static scenarios is employed in the model.

In terms of the material modelling, the nonlinear stress-strain relationship of concrete in compression is described using Eq. 16, in accordance with Eurocode 2 [14]:

$$
\sigma_{c}=\left(\frac{k\left(\frac{\varepsilon_{c}}{\varepsilon_{c l}}\right)-\left(\frac{\varepsilon_{c}}{\varepsilon_{c l}}\right)^{2}}{1+(k-2)\left(\frac{\varepsilon_{c}}{\varepsilon_{c l}}\right)}\right) f_{c m} \text { for } 0 \leq \varepsilon_{\mathrm{c}} \leq \varepsilon_{\mathrm{cu}}
$$

In this expression, $f_{c m}$ is the ultimate compressive strength of concrete (determined as $\left.f_{c m}=f_{c k}+8\right), f_{c k}$ is the characteristic 
cylinder strength of the concrete, $k$ is a parameter (found from $\left.k=1.05 E_{c m} \frac{\varepsilon_{c l}}{f_{c m}}\right), E_{c m}$ is the elastic modulus of concrete (calculated as $\left.E_{c m}(G P a)=22\left(0.1 f_{c m}\right)^{0.3}\right), \varepsilon_{c l}$ is the concrete strain at the peak stress (given as $\left.\varepsilon_{c 1}(\% o)=0.7\left(f_{c m}\right)^{0.31} \leq 2.8\right), \quad \varepsilon_{c u}$ is the nominal ultimate strain, which is given by $\varepsilon_{c u}(\% o)=2.8+27\left[\left(98-f_{c m}\right) / 100\right]^{4}$ for $f_{c k} \geq$ $50 \mathrm{~N} / \mathrm{mm}^{2}$, otherwise it has a value of $3.5 \%$. The material model for the stainless steel beam is described using the two-stage stress-strain relationship proposed Rasmussen [12]. The full material model is presented in Eq. (17):

$$
\varepsilon=\left\{\begin{array}{c}
\frac{\sigma}{E}+0.002\left(\frac{\sigma}{\sigma_{0.2}}\right)^{n} \text { for } 0 \leq \sigma \leq \sigma_{0.2} \\
\varepsilon_{0.2}+\frac{\sigma-\sigma_{0.2}}{E_{2}}+\varepsilon_{u p}^{*}\left(\frac{\sigma-\sigma_{0.2}}{\sigma_{u}-\sigma_{0.2}}\right)^{m} \\
\text { for } \sigma_{0.2} \leq \sigma \leq \sigma_{u}
\end{array}\right.
$$

where $\varepsilon_{u p}^{*}=\varepsilon_{u^{-}}-\varepsilon_{0.2^{-}} \frac{\sigma_{u^{-}-\sigma_{0.2}}}{E_{2}}$ and $\varepsilon$ and $\sigma$ are the uniaxial strain and stress, respectively.

\section{Validation of the analytical model}

The plastic bending capacity results obtained numerically are compared with those predicted using simplified analytical analysis proposed in Section 2. Two cross-sections are used in the validation and their geometries are presented in the Table 1 .

Table 1: Geometry of the composite beams used for the validation study (all dimensions in $\mathrm{mm}$ )

\begin{tabular}{ccccccc}
\hline Name & $\boldsymbol{b}_{\boldsymbol{c}}$ & $\boldsymbol{t}_{\boldsymbol{c}}$ & $\boldsymbol{t}_{\boldsymbol{w}}$ & $\boldsymbol{h}$ & $\boldsymbol{b}_{\boldsymbol{f}}$ & $\boldsymbol{t}_{\boldsymbol{f}}$ \\
\hline $\mathrm{B} 1$ & 1200 & 100 & $\begin{array}{l}10 \\
2\end{array}$ & 304.8 & 152.4 & 18.2 \\
$\mathrm{~B} 2$ & 1500 & 100 & 12 & 400 & 190 & 18.2 \\
\hline
\end{tabular}

Six different grades of stainless steel are used in the comparison, and their material properties are presented in Table 2 and taken from Eurocode 3-Part 1-4 [18].
Table 2: Material properties of stainless steel [18]

\begin{tabular}{ccccc}
\hline Grade & $\begin{array}{c}\boldsymbol{\sigma}_{\mathbf{0 . 2}} \\
(\mathbf{M P a})\end{array}$ & $\begin{array}{c}\boldsymbol{\sigma}_{\mathbf{u}} \\
(\mathbf{M P a})\end{array}$ & $\mathbf{n}$ & $\begin{array}{c}\mathbf{A} \\
(\boldsymbol{\%})\end{array}$ \\
\hline 1.4003 & 280 & 450 & 7 & 51 \\
1.4016 & 260 & 450 & 6 & 38 \\
1.4512 & 210 & 380 & 9 & 44 \\
1.4571 & 220 & 520 & 7 & 40 \\
1.4406 & 280 & 580 & 8 & 40 \\
1.4362 & 400 & 630 & 5 & 20 \\
\hline
\end{tabular}

Tables 3 and 4 present the results from the analysis including the bending moment capacities obtained from the numerical analysis $\left(M_{F E}\right)$ and the simplified analytical method $\left(M_{\text {analytical }}\right)$. Also included in the tables is the ratio of $M_{F E}$ to $M_{E C 4}$, which is the bending moment capacity obtained using Eurocode 4 [19] assuming that the stainless steel cross-section is stressed to $\sigma_{0.2}$ and strain hardening of the stainless steel is neglected. It is observed that a very good agreement is achieved between results obtained numerically with those obtained from simplified analytical expression. For beam B1, the analytical model slightly underestimates the bending moment capacity in all cases but the error is within 5\%. On the other hand, for B2, the analytical model generally underestimates the capacity (in all cases except one) but only by up to $2.5 \%$. Therefore, it can be deduced that the proposed analytical solution provides a reliable and accurate prediction of the bending moment capacity of stainless steel-concrete composite beams with full shear connection. Additionally it is noteworthy that the bending moment capacity predicted when strain hardening is ignored provides very conservative results and hence uneconomical design, highlighting that current design provisions are not appropriate or efficient for composite beams made using stainless steel. 
Table 3: Comparison between the numerical and analytical bending moment capacities for beam B1

\begin{tabular}{cccc}
\hline $\begin{array}{c}\text { Stainless } \\
\text { steel } \\
\text { grade }\end{array}$ & $\begin{array}{c}\text { Concrete } \\
\text { grade }\end{array}$ & $\begin{array}{c}\frac{\boldsymbol{M}_{\text {analytical }}}{\boldsymbol{M}_{\boldsymbol{F E}}} \\
(\%)\end{array}$ & $\begin{array}{c}\boldsymbol{M}_{\boldsymbol{E C} 4} \\
\boldsymbol{\boldsymbol { M } _ { F E }} \\
(\%)\end{array}$ \\
\hline 1.4003 & $\mathrm{C} 40$ & -3.7 & -14 \\
1.4016 & $\mathrm{C} 40$ & -4.4 & -16.8 \\
1.4512 & $\mathrm{C} 40$ & -4.6 & -18.5 \\
1.4571 & $\mathrm{C} 50$ & -5 & -24.7 \\
1.4406 & $\mathrm{C} 50$ & -4.8 & -19.7 \\
1.4362 & $\mathrm{C} 50$ & -2.2 & -12.8 \\
\hline
\end{tabular}

Table 4: Comparison between the numerical and analytical bending moment capacities for beam B2

\begin{tabular}{|c|c|c|c|}
\hline $\begin{array}{c}\text { Stainless } \\
\text { steel grade }\end{array}$ & $\begin{array}{c}\text { Concrete } \\
\text { grade }\end{array}$ & 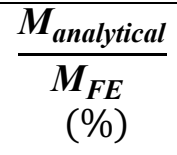 & $\begin{array}{r}\frac{M_{E C 4}}{M_{F E}} \\
(\%)\end{array}$ \\
\hline 1.4003 & $\mathrm{C} 40$ & -0.2 & -12 \\
\hline 1.4016 & $\mathrm{C} 40$ & -0.5 & -14.5 \\
\hline 1.4512 & $\mathrm{C} 40$ & -1.8 & -17.1 \\
\hline 1.4571 & C50 & -2.3 & -23.8 \\
\hline 1.4406 & C50 & -1.05 & -17.8 \\
\hline 1.4362 & C50 & 1.2 & -11 \\
\hline
\end{tabular}

In the following analysis, the simplified analytical model is used to investigate the effect of different stainless steel and concrete properties on the bending moment capacity of stainless steel-concrete composite beams. In this investigation, composite beam B1 is used to illustrate the behaviour. The reference bending moment $\left(M_{\text {analytical }}^{\text {ref }}\right)$ is obtained for stainless steel with $\sigma_{0.2}=200 \mathrm{MPa}, \sigma_{u}=500 \mathrm{MPa}, n=5$ and $A=0.4$, and $\mathrm{C} 30$ concrete. The bending moment capacity determined using thee simplified analytical model $\left(M_{\text {analytical }}\right)$ is calculated for a wide range of material properties, as shown in Table 5 .

Table 5: Range of material parameters used in the comparison

\begin{tabular}{cccc}
\hline $\boldsymbol{n}$ & $\boldsymbol{\sigma}_{0.2}(\mathbf{M P a})$ & $\boldsymbol{\sigma}_{u}(\mathbf{M P a})$ & $\boldsymbol{f}_{\boldsymbol{c}}$ (MPa) \\
\hline $5-21$ & $200-350$ & $500-700$ & $30-50$ \\
\hline
\end{tabular}

Fig. 3 presents the variation in predicted bending moment capacity as a function of (a) $n$, (b) $\sigma_{0.2}$, (c) $\sigma_{u}$ and (d) $f_{c}$. It is noteworthy that the bending moment capacity of stainless steelconcrete composite beams reduces with an increase of the strain hardening coefficient $n$. Furthermore, the bending moment capacity significantly increases with the increase of the proof stress $\sigma_{0.2}$ and slightly increases for relatively larger values of ultimate stress $\sigma_{u}$.

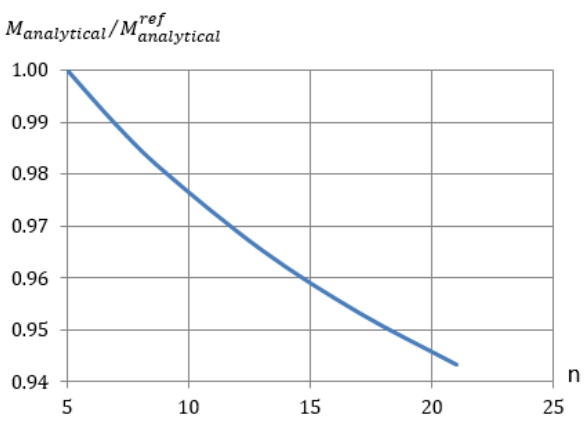

(a)

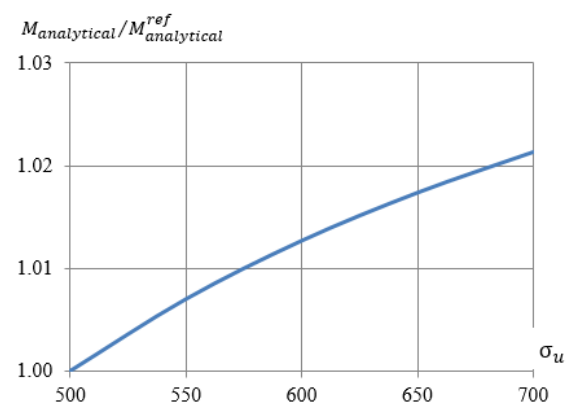

(b)

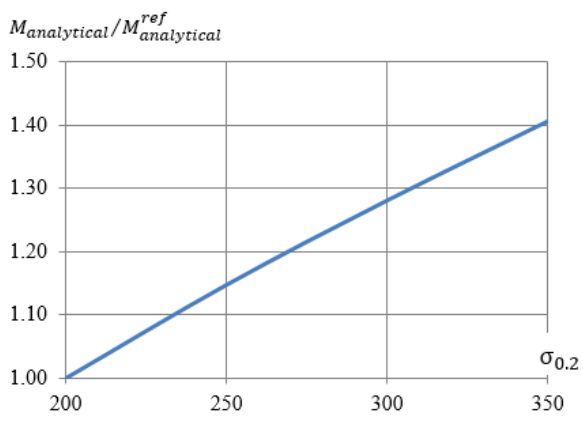

(c)

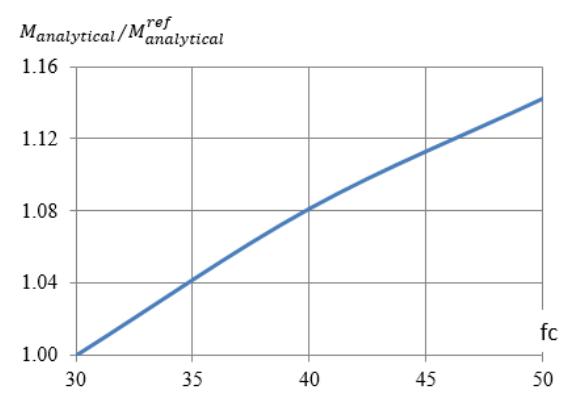

(d)

Fig. 3: Variation in the bending moment capacity as a function of (a) $n$, (b) $\sigma_{0.2}$, (c) $\sigma_{u}$ and (d) $f_{c}$ 


\section{Conclusions}

Current design codes for steel-concrete composite beams neglect strain hardening of the steel member in design strength calculations. Although this is a reasonable assumption for carbon steel, stainless steel is a very ductile material which demonstrates significant levels of strain hardening. Moreover, although stainless steel offers a number of significant advantages compared with carbon steel (e.g. corrosion resistance, ductility, etc.), it is an expensive material in terms of the initial cost and therefore, it is important to adopt an efficient design procedure in order to minimise the material requirements. In the current paper, a simplified analytical solution for calculating the bending moment capacity of stainless steel-concrete composite beams full shear connection is proposed. The model is validated using numerical results obtained from a finite element model, developed in ABAQUS. It is concluded that the simplified analytical solution is reliable and provides a straight-forward design tool for practical engineers. It is also concluded that the ultimate stress of stainless steel has a negligible effect on the bending moment capacity of stainless steel-concrete composite beams, whereas other material parameters such as the nonlinear parameter, $n$, and the yield stress are more influential.

\section{References}

[1] Rossi B. Discussion on the use of stainless steel in constructions in view of sustainability, Thin Walled Structures 2014, 83: 182-189.

[2] Han LH, Chen F, Liao FY, Tao Z, Uy B. Fire performance of concrete filled stainless steel tubular columns. Engineering Structures 2013, 56: 165-181.

[3] Zhao O, Rossi B, Gardner L, Young B. Behaviour of structural stainless steel crosssections under combined loading-Part I: experimental study. Engineering Structures 2015, 89: 236-246.

[4] Zhao O, Gardner L, Young B. Buckling of ferritic stainless steel members under combined axial compression and bending. Journal of Constructional Steel Research 2016, 117: 35-48.

[5] Zhao O, Gardner L, Young B. Structural performance of stainless steel circular hollow sections under combined axial load and bendingPart 1: Experiments and numerical modelling. Thin-Walled Structures 2016, 101: 231-239.

[6] Han LH, Chen F, Liao FY, Tao Z, Uy B. Fire performance of concrete filled stainless steel tubular columns. Engineering Structures 2013, 56: $165-181$

[7] Tao Z, Uy B, Liao FY, Han LH. Nonlinear analysis of concrete-filled square stainless steel stub columns under axial compression. Journal of Constructional Steel Research 2011, 67(11): 1719-1732.

[8] Patton ML, Singh KD. Finite element modelling of concrete-filled lean duplex stainless steel tubular stub columns. International Journal of Steel Structures 2014, 14(3): 619-32.

[9] Gardner L, Ashraf M. Structural design for nonlinear metallic materials. Engineering Structures 2006, 28(6): 926-934.

[10] Gardner L, Nethercot DA. Structural stainless steel design: a new approach. Structural Engineer 2004, 82: 21-30.

[11] Gardner L, Yun X, Macorini L, Kucukler M. Hot-rolled steel and steel-concrete composite design incorporating strain hardening. Structures 2017, 9: 21-28.

[12] Rasmussen KJ. Full-range stress-strain curves for stainless steel alloys. Journal of Constructional Steel Research 2003, 59(1): 4761.

[13] Abdella K. Inversion of a full-range stress-strain relation for stainless steel alloys. International Journal of Non-Linear Mechanics 2006, 41(3): 456-63.

[14] CEN. European Committee for Standardization EN 1992-1-1, Eurocode 2. Design of concrete structures - Part 1-1: General rules and rules for buildings. Brussels, 2004.

[15] Shamass R, Cashell KA. Behaviour of composite beams made using high strength steel. Structures 2017, 12: 88-101.

[16]ABAQUS. ABAQUS/standard versión 6.14 user's manual: volumnes I-II. Pawtucket, Rhode Island: Hibbit, Karlsson \& Sorenson, Inc.

[17] Ollgaard JG. Shear strength of stud connectors in lightweight and normal-weight concrete. AISC Engineering Journal 1971: 55-64.

[18] CEN. European Committee for Standardization, EN 1993-1-4, Eurocode 3. Design of steel structures - Part 1-4: General rules supplementary rules for stainless steels. Brussels; 2006.

[19] CEN. European Committee for Standardization EN 1994-1-1, Eurocode 4. Design of composite steel and concrete structures - Part 1-1: General rules and rules for buildings. Brussels; 2005. 